\title{
Early versus late tracheostomy after decompressive craniectomy for stroke
}

\author{
Michael P. Catalino ${ }^{1}$, Feng-Chang Lin², Nathan Davis', Keith Anderson ${ }^{3}$, Casey Olm-Shipman ${ }^{1,4}$ \\ and J. Dedrick Jordan ${ }^{1,4^{*}}$
}

\begin{abstract}
Background: Stroke patients requiring decompressive craniectomy are at high risk of prolonged mechanical ventilation and ventilator-associated pneumonia (VAP). Tracheostomy placement may reduce the duration of mechanical ventilation. Predicting which patients will require tracheostomy and the optimal timing of tracheostomy remains a clinical challenge. In this study, the authors compare key outcomes after early versus late tracheostomy and develop a useful pre-operative decision-making tool to predict post-operative tracheostomy dependence.

Methods: We performed a retrospective analysis of prospectively collected registry data. We developed a propensityweighted decision tree analysis to predict tracheostomy requirement using factors present prior to surgical decompression. In addition, outcomes include probability functions for intensive care unit length of stay, hospital length of stay, and mortality, based on data for early ( $\leq 10$ days) versus late ( $>10$ days) tracheostomy.

Results: There were 168 surgical decompressions performed on patients with acute ischemic or spontaneous hemorrhagic stroke between 2010 and 2015. Forty-eight patients (28.5\%) required a tracheostomy, 35 (20.8\%) developed VAP, and 126 (75\%) survived hospitalization. Mean ICU and hospital length of stay were 15.1 and 25.8 days, respectively. Using GCS, SOFA score, and presence of hydrocephalus, our decision tree analysis had $63 \%$ sensitivity and $84 \%$ specificity for predicting tracheostomy requirement. The early group had fewer ventilator days ( 7.3 versus $15.2, p<0.001)$ and shorter hospital length of stay ( 28.5 versus 44.4 days, $p=0.014$ ). VAP rates and mortality were similar between the two groups. Withdrawal of treatment interventions shortly post-operatively confounded mortality outcomes.
\end{abstract}

Conclusion: Early tracheostomy shortens duration of mechanical ventilation and length of stay after surgical decompression for stroke, but it did not impact mortality or VAP rates. A decision tree is a practical tool that may be helpful in guiding pre-operative decision-making with patients' families.

Keywords: Decompression, Ischemic stroke, Hemorrhagic stroke, Tracheostomy timing, Ventilator-associated pneumonia

\section{Background}

Mechanically ventilated stroke patients are at risk for ventilator-associated pneumonia (VAP) and prolonged stay in intensive care units (ICU) [1-3]. Recent reviews cite the incidence of VAP to be 1-9 occurrences per 1000 ventilator days and suggest its pathogenesis to be multifactorial with timing, duration of endotracheal ventilation, host factors, and virulence of invading bacteria all

\footnotetext{
*Correspondence: dedrick@unc.edu

${ }^{1}$ Department of Neurosurgery, University of North Carolina School of

Medicine, 170 Manning Drive, Campus Box 7025, Chapel Hill, NC 27599-7025, USA

${ }^{4}$ Department of Neurology, University of North Carolina, 170 Manning Drive, Campus Box 7025, Chapel Hill, NC, USA

Full list of author information is available at the end of the article
}

contributing [4]. Patients with ischemic and hemorrhagic stroke can often wean rapidly from the ventilator after tracheostomy [5]. There is little evidence to guide timing of tracheostomy in patients with large hemispheric infarctions [6]. Generally, tracheostomy may be considered after 7-14 days if extubation is not feasible. Studies have looked at tracheostomy performed as early as hospital day 4 [7], but the definition of "early" and "late" varies widely in the literature [7-11]. Studies have shown a linear relationship between tracheostomy timing and ICU length of stay [3]. Furthermore, delayed tracheostomy may place patients at undue risk of pneumonia from prolonged mechanical ventilation [11-14]. 
The TRACH score [14] and SETscore [15] are two of the most comprehensive tools, among many that are used for predicting tracheostomy in patients with cerebrovascular injury [16]. The reported sensitivity of the TRACH score is $94 \%$ and has a specificity of $83 \%$ to predict extubation. Furthermore, the SETscore looks at neurological function, brain lesion factors, and general organ function to assess likelihood requiring greater than 2 weeks of ventilator support in stroke patients in the ICU [15]. A SETscore of 8 returned an optimum sensitivity of $65.4 \%$ and specificity of $73.5 \%$. These are two helpful tools within a growing body of literature on this topic. In critically ill patients, studies are inconclusive but suggest a decrease in mortality and ICU length of stay and lower sedative requirement after early tracheostomy. [8, 17] The SETPOINT pilot study decreased ICU and 6-month mortality after tracheostomy placement 1-3 days after intubation in patients with all strokes, including subarachnoid hemorrhage, but indicated no change in ICU length of stay [9], although half of the patients randomized to standard tracheostomy died prior to receiving the intervention. We are critical in our interpretation of current literature as large wellcontrolled studies are still lacking, and those present are considerably heterogeneous. In one trial, about half of the patients assigned to late tracheostomy did not require the intervention at all [7]. Our objectives were to use our robust database and propensity weight methods to identify which factors predicted the need for tracheostomy in stroke patients requiring surgical decompression, as well as to analyze the relationship between the timing of tracheostomy, incidence of VAP, rate of inhospital mortality, and ICU and hospital length of stay.

\section{Methods}

\section{Data registry}

The University of North Carolina (UNC) Neuroscience Intensive Care Unit (NSICU) patient registry is a prospectively collected database of all NSICU patients. Institutional Review Board approval was obtained to access the database for research purposes (IRB no. 152372). The database was queried. Inclusion criteria were as follows: adult patients, presentation between May 2010 and September 2015, ischemic or hemorrhagic stroke, and decompressive craniectomy. Data was extracted directly from the database, and patient records were reviewed for additional variables as needed. There were no exclusion criteria, and thus, all patients meeting the inclusion criteria were included in the initial analysis. Patients with missing variables were still included; however, specific missing variables excluded patients from the denominator of analyses where data was not available. In the final mortality analysis, patients who died on comfort care were excluded.

\section{Data analysis}

Timing of tracheostomy was expressed in terms of poststroke day or hospital day if the date of injury was indeterminate. A 10-day cutoff was preselected based on previous literature from a recent Cochrane Review [8]. It fell between the routine tracheostomy timing at our institution (7-14 days) and thus was also feasible to study using our database. The treatment group (early) included all patients receiving tracheostomy at or before stroke/hospital day 10, and the control group (late) was those who received a tracheostomy after day 10 .

The primary objectives were to develop a predictive model for tracheostomy and compare outcomes for early versus late tracheostomy. Primary outcomes included mortality, ICU length of stay, hospital length of stay, and ventilator-associated pneumonia. Propensity weighting was used to predict the probability of tracheostomy after identifying crude predictors through bivariate analysis. We used propensity scores to control for differences in measured covariates between early and late tracheostomy cohorts by first estimating the probability of receiving tracheostomy based on crude bivariate analysis in Table 2 . After weighting, this process leads to a pseudo-population, whose covariate distribution can be matched between early and late tracheostomy cohorts. This not only removes confounding by measured covariates, but also allows us to estimate the association between timing of tracheostomy and outcomes. We report percentages only in the final analysis because the actual counts are based on the pseudo-population. Variables considered for inclusion in the propensity weights were Glasgow Coma Score (GCS), time to surgery, hydrocephalus, location of stroke, and Sequential Organ Failure Assessment (SOFA) score. Time to surgery was not a clinically meaningful predictor after sensitivity analyses, and thus, it was not used in the final weights. GCS has been described as a predictor for tracheostomy after craniectomy for traumatic brain injury, but not for stroke, and thus, we felt it was a meaningful variable to include [18]. Hydrocephalus was defined as any neurological deterioration attributable to elevated ICP, which subsequently required cerebrospinal fluid diversion via a ventriculostomy drain. All primary outcomes were compared using propensity weights. Sensitivity analysis was performed for tracheostomy timing and primary outcomes.

\section{Results}

There were 168 patients who received surgical decompression following a stroke (Fig. 1). Descriptive patient characteristics are reported in Table 1. Average GCS on admission was 9.3 , average time to surgery was 1.7 days, and average SOFA score was 6.5. There were 131 hemorrhagic and 37 ischemic strokes, of which 37 (28.2\%) and 11 (29.7\%), respectively, required a tracheostomy. Indications for tracheostomy included failure to wean mechanical ventilation for 


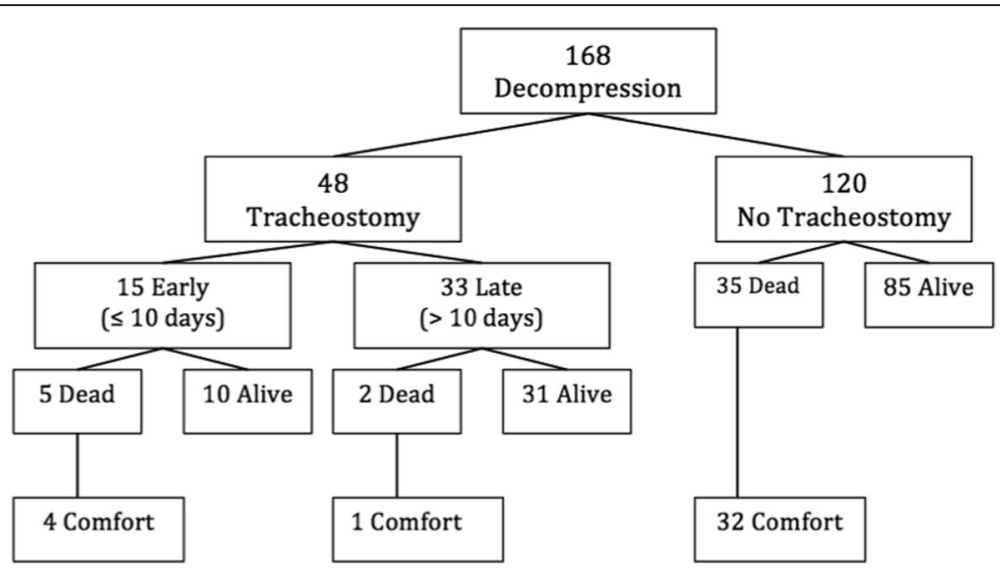

Fig. 1 Flow chart showing the number of patients who underwent decompression for stroke (ischemic or hemorrhagic), those who received a tracheostomy, and survival, including those who were excluded from the final analysis due to death while on comfort-measures-only status

a prolonged period, neurological status that precludes extubation, and multiple failed extubation. Additionally, 35 (20.8\%) patients developed VAP. On average, patients contracted VAP 2 days prior to receiving their tracheostomy and 9 days after admission (Table 1). Patients who required tracheostomy had longer ICU length of stay $(27.8$ versus 10.0 days, $p<0.001)$ and a longer duration of mechanical ventilation (13.0 versus 6.3 days, $p<0.001$ ); however, these patients did not demonstrate a significantly longer mean length of hospital stay.

Bivariate analysis comparing covariates among those who received a tracheostomy and those who did not are shown in Table 2. These covariates were used to build propensity weights as shown in Tables 3 and 4. Duration of mechanical ventilation was the only significant variable that correlated with VAP in multivariate regression modeling. Lower GCS, higher SOFA, and hydrocephalus all were associated with higher likelihood of receiving tracheostomy (Tables 3 and 4), and these variables were included in the decision tree analysis (Fig. 2).

\section{Decision tree analysis}

GCS was the most important predictor for tracheostomy. Patients with a GCS less than 8, SOFA greater than 5 , and hydrocephalus had the highest likelihood of requiring tracheostomy. Combining these classification criteria, the sensitivity is $63 \%$ and the specificity is $84 \%$. Figure 2 shows the decision tree analysis, and the caption provides a detailed explanation of its interpretation.

\section{Primary outcomes and tracheostomy timing}

Fifteen patients $(31.2 \%)$ received a tracheostomy prior to hospital day 10, and 33 patients received a tracheostomy after day 10 (68.8\%). Propensity-weighted outcomes comparing no tracheostomy versus tracheostomy were reviewed. Patients who received a tracheostomy had comparable mortality (after excluding those who transitioned to comfort measures), higher VAP incidence, and longer ICU length of stay (Additional file 1: Table S2). Early tracheostomy significantly predicted mortality compared to late tracheostomy [10/15 (33.3\%) versus $2 / 33$ (6.1\%), respectively, $p=0.006$; Table 3 ] although this was completely explained by early withdrawal of treatment and death while on comfort care (Table 4). Early tracheostomy did not protect against VAP compared to late tracheostomy (40.0\% versus $36.4 \%, p=0.614$ ). Early tracheostomy did lead to less overall duration of ventilator dependence. Mean ventilator days for early tracheostomy was 7.3 versus 15.2 days for late tracheostomy $(p<0.001)$. Early tracheostomy was associated with a trend toward reducing the ICU length of stay, 20.1 versus 31.5 days, although this difference was not significantly different ( $p=0.073$; Table 3$)$. Early tracheostomy significantly reduced hospital length of stay from 44.4 to 28.5 days ( $p=0.014$; Table 3 ).

VAP incidence rate was similar for both groups, $40 \%$ for early versus $36 \%$ for late tracheostomy $(p=0.614)$. If the cutoff is changed to day 7 or earlier, the VAP is much lower for the early group (20 versus $40 \%, p=0.821$ ), but statistical significance is not reached due to too few patients in this group. For discharge location, early tracheostomy showed a trend toward more favorable discharge locations (40.0 versus $29.0 \%, p=0.192$; Table 4). According to propensity-weighted probability functions for hospital discharge, the early tracheostomy group had a significantly shorter hospital length of stay (Fig. 3). However, propensity-adjusted mortality rate analysis resulted in a significantly higher mortality rate in patients who received an early tracheostomy (33.3 versus 6.1\%, $p=0.006$; Table 3 and Fig. 4a). In addition, patients with early tracheostomies still trended toward favorable discharge (home or to rehab) compared to those with late tracheostomies (40.0\% versus $29.0 \%$, respectively) with similar VAP rates $(36.4 \%$ versus $37.5 \%$, respectively; Table 4). 
Table 1 Patient demographics and clinical factors by primary stroke etiology (hemorrhagic or ischemic)

\begin{tabular}{|c|c|c|c|c|}
\hline & Total & $\mathrm{ICH}$ & Ischemic & $p$ value \\
\hline N & 168 & $131(78 \%)$ & $37(22 \%)$ & \\
\hline Age, mean (SD) & $55.3(15.3)$ & $55.3(16.2)$ & $55.2(12.0)$ & 0.116 \\
\hline Male & $91(54 \%)$ & $65(50 \%)$ & $26(70 \%)$ & 0.039 \\
\hline \multicolumn{5}{|l|}{ Race } \\
\hline White & $86(57 \%)$ & $68(59 \%)$ & $18(53 \%)$ & \multirow[t]{3}{*}{0.547} \\
\hline African American & $51(34 \%)$ & $37(32 \%)$ & $14(41 \%)$ & \\
\hline Other & $13(9 \%)$ & $11(9 \%)$ & $2(6 \%)$ & \\
\hline BMI, mean (SD) & $28.1(7.4)$ & $27.6(7.6)$ & $29.7(6.2)$ & 0.148 \\
\hline Myocardial infarction & $8(5 \%)$ & $6(5 \%)$ & $2(5 \%)$ & 1.000 \\
\hline Congestive heart failure & $9(5 \%)$ & $3(2 \%)$ & $6(16 \%)$ & 0.004 \\
\hline Peripheral vascular disease & $11(7 \%)$ & $6(5 \%)$ & $5(13 \%)$ & 0.067 \\
\hline Dementia & $1(1 \%)$ & $1(1 \%)$ & $0(0 \%)$ & 1.000 \\
\hline Cerebrovascular disease & $23(14 \%)$ & 19 (15\%) & $4(11 \%)$ & 0.787 \\
\hline Chronic lung disease & $17(10 \%)$ & $14(11 \%)$ & $3(8 \%)$ & 0.766 \\
\hline Ulcer & $3(2 \%)$ & $3(2 \%)$ & $0(0 \%)$ & 1.000 \\
\hline Chronic liver disease & $6(4 \%)$ & $6(5 \%)$ & $0(0 \%)$ & 0.340 \\
\hline Diabetes & $30(18 \%)$ & $18(14 \%)$ & $12(32 \%)$ & 0.015 \\
\hline Moderate-severe kidney disease & $13(8 \%)$ & $13(10 \%)$ & $0(0 \%)$ & 0.074 \\
\hline Diabetes with organ damage & $4(2 \%)$ & $4(3 \%)$ & $0(0 \%)$ & 0.577 \\
\hline Tumor & $10(6 \%)$ & $9(7 \%)$ & $1(3 \%)$ & 0.461 \\
\hline Leukemia & $3(2 \%)$ & $3(2 \%)$ & $0(0 \%)$ & 1.000 \\
\hline Lymphoma & $0(0 \%)$ & $0(0 \%)$ & $0(0 \%)$ & NA \\
\hline Moderate-severe liver disease & $1(1 \%)$ & $1(1 \%)$ & $0(0 \%)$ & 1.000 \\
\hline Malignant tumor & $9(5 \%)$ & $8(6 \%)$ & $1(3 \%)$ & 0.685 \\
\hline Metastasis & $5(3 \%)$ & $5(4 \%)$ & $0(0 \%)$ & 0.588 \\
\hline AIDS & $3(2 \%)$ & $1(1 \%)$ & $2(5 \%)$ & 0.124 \\
\hline Hosp. LOS, mean (SD) & $25.8(27.0)$ & $27.1(29.2)$ & $21.2(16.2)$ & 0.246 \\
\hline \multicolumn{5}{|l|}{ Discharge location } \\
\hline SNF & $35(27.8 \%)$ & $26(26.8 \%)$ & $9(31.0 \%)$ & \multirow[t]{5}{*}{0.560} \\
\hline AIR & $54(42.9 \%)$ & $40(41.2 \%)$ & $14(48.3 \%)$ & \\
\hline Home & $25(19.8 \%)$ & $22(22.7 \%)$ & $3(10.3 \%)$ & \\
\hline LTAC & $10(7.9 \%)$ & $7(7.2 \%)$ & $3(10.3 \%)$ & \\
\hline Hospice & $2(1.6 \%)$ & $2(2.1 \%)$ & $0(0.0 \%)$ & \\
\hline \multicolumn{5}{|l|}{ Discharge condition } \\
\hline Alive & $126(75.0 \%)$ & $97(74.0 \%)$ & $29(78.4 \%)$ & \multirow[t]{3}{*}{0.671} \\
\hline Dead without comfort care & $5(3.0 \%)$ & $4(3.1 \%)$ & $1(2.7 \%)$ & \\
\hline Dead with comfort care & 37 (22.0\%) & $30(22.9 \%)$ & 7 (18.9\%) & \\
\hline ICU LOS, mean (SD) & $15.1(16.2)$ & $16.0(17.7)$ & $11.9(8.8)$ & 0.190 \\
\hline Readmission to ICU & $37(22.2 \%)$ & $26(20.0 \%)$ & $11(29.7 \%)$ & 0.261 \\
\hline GCS on adm., mean (SD) & $9.3(3.7)$ & $8.9(3.8)$ & $10.6(3.2)$ & 0.012 \\
\hline Admission mRS, mean (SD) & $4.9(0.4)$ & $4.9(0.5)$ & $5.0(0.0)$ & 0.068 \\
\hline SOFA score, mean (SD) & $6.5(2.8)$ & $6.6(2.8)$ & $6.1(2.7)$ & 0.331 \\
\hline NIHSS, mean (SD) & $18.3(7.2)$ & - & $18.3(7.2)$ & NA \\
\hline
\end{tabular}


Table 1 Patient demographics and clinical factors by primary stroke etiology (hemorrhagic or ischemic) (Continued)

\begin{tabular}{|c|c|c|c|c|}
\hline & Total & $\mathrm{ICH}$ & Ischemic & $p$ value \\
\hline \multicolumn{5}{|l|}{ Location } \\
\hline Bilateral supratentorial & $8(4.8 \%)$ & $8(6.1 \%)$ & $0(0.0 \%)$ & \multirow[t]{4}{*}{0.456} \\
\hline Infratentorial & $32(19.0 \%)$ & $24(18.3 \%)$ & $8(21.6 \%)$ & \\
\hline Left supratentorial & $57(33.9 \%)$ & $45(34.4 \%)$ & $12(32.4 \%)$ & \\
\hline Right supratentorial & $71(42.3 \%)$ & $54(41.2 \%)$ & $17(45.9 \%)$ & \\
\hline ICH score, mean (SD) & $1.81(0.95)$ & $1.81(0.95)$ & - & NA \\
\hline $\mathrm{IVH}$ & $62(48.1 \%)$ & $62(48.1 \%)$ & - & \multirow[t]{2}{*}{ NA } \\
\hline Hydrocephalus & $88(68.8 \%)$ & $88(68.8 \%)$ & - & \\
\hline Time to surgery, mean (SD) & $1.70(3.6)$ & $1.70(3.9)$ & $1.68(2.4)$ & 0.969 \\
\hline Time to ventilator, mean (SD) & $0.65(2.4)$ & $0.63(2.7)$ & $0.73(1.3)$ & 0.821 \\
\hline Duration of ventilator, mean (SD) & $8.1(7.7)$ & $8.8(8.1)$ & $5.9(5.4)$ & 0.051 \\
\hline \# failed weans, mean (SD) & $0.37(0.56)$ & $0.36(0.57)$ & $0.38(0.55)$ & 0.873 \\
\hline Tracheostomy & $48(28.6 \%)$ & $37(28.2 \%)$ & $11(29.7 \%)$ & 0.840 \\
\hline Hosp tracheostomy day, mean (SD) & $13.8(7.2)$ & $14.4(7.9)$ & $11.8(4.0)$ & 0.301 \\
\hline Duration tracheostomy, mean (SD) & $29.8(28.3)$ & $30.2(27.2)$ & $28.3(33.3)$ & 0.912 \\
\hline Tracheostomy at discharge & $39(81.3 \%)$ & $28(75.7 \%)$ & $11(100 \%)$ & 0.070 \\
\hline Total TRACH score & $2.3(2.4)$ & $2.3(2.4)$ & - & NA \\
\hline Number of VAP, mean (SD) & $0.56(1.22)$ & $0.59(1.27)$ & $0.46(1.04)$ & 0.574 \\
\hline Hospital VAP day, mean (SD) & $9.5(11.2)$ & $9.2(11.6)$ & $10.3(10.6)$ & 0.826 \\
\hline Tracheostomy VAP day, mean (SD) & $-2(16.6)$ & $-4.2(17.8)$ & $3.2(13.4)$ & 0.421 \\
\hline
\end{tabular}

AIR acute inpatient rehabilitation, GCS Glasgow Coma Score, ICU intensive care unit, LOS length of stay, LTAC long-term acute care, SD standard deviation, SNF skilled nursing facility, SOFA Sequential Organ Failure Assessment

\section{Discussion}

Predicting who will require a tracheostomy after decompressive surgery for ischemic stroke or intracerebral hemorrhage remains a challenge. Furthermore, we, and others, have shown that the risk of ventilator-associated pneumonia is strongly associated with duration of mechanical ventilation [2]. Predicting which of these critically brain-injured patients will ultimately need a tracheostomy would be helpful when discussing treatment options with families. We have developed a decision tree, based on key variables present on admission (GCS, SOFA score, and presence of hydrocephalus; Fig. 2), which can help guide clinical judgment as to who may be a candidate for tracheostomy. This adds to the repertoire of clinical decision-making tools available to help expedite tracheostomy placement and free patients from the ventilator. Here, we argue that early tracheostomy may expedite ICU and hospital discharge, but its impact on reducing the risk of ventilator-associated pneumonia and mortality is still unclear.

In the initial TRACH score study, all patients with TRACH score $>2.0$ required a tracheostomy, while none with a score $<0.7$ required a tracheostomy. In our data, $\mathrm{ICH}$ patients requiring decompressive surgery and no tracheostomy had a mean TRACH score of 2.2 and 3.2 for those who did have a tracheostomy $(p=0.041)$. Thus, if using the TRACH score cutoff of 2, as in the original study, many of our patients would have received a tracheostomy that did not ultimately need one [14].

Our decision analysis shows that, in patients with a GCS less than 8, SOFA greater than 5, and hydrocephalus requiring a ventriculostomy, the sensitivity is $63 \%$ and the specificity is $84 \%$ for predicting tracheostomy requirement. This results in a positive predictive value of $61.2 \%$ and a negative predictive value of $85 \%$. Our primary outcome data is similar to the results of a recent meta-analysis by McCredie and colleagues looking at early tracheostomy in patients with severe acute brain injury [19]. They found that although early tracheostomy reduced length of ICU stay, it did not have a significant mortality benefit. These results are in contrast to another study from Brazil which showed a drastically reduced 28-day mortality rate in early tracheostomy patients (9 versus $46 \%, p=0.049$ ) even with a small sample size $(n=28)$ [20]. Notably, GCS and SOFA score were similar in the two groups, serving as an internal control. However, they also noted an extremely high rate of VAP in the late group (54\% in the early group and $70 \%$ in the late group), whereas our VAP rate was $40.0 \%$ in the early group and $36.4 \%$ in the late group. This may help explain the mortality benefit in their population, since higher VAP rates combined with rapid weaning 
Table 2 Bivariate analysis for receiving a tracheostomy

\begin{tabular}{|c|c|c|c|}
\hline & No trach & Trach & $p$ value \\
\hline N & 120 & 48 & \\
\hline \multicolumn{4}{|l|}{ Diagnosis } \\
\hline $\mathrm{ICH}$ & $94(78.3 \%)$ & $37(77.1 \%)$ & 0.860 \\
\hline Ischemic & $26(21.7 \%)$ & $11(22.9 \%)$ & \\
\hline Age, mean (SD) & $56.4(14.6)$ & $52.4(16.9)$ & 0.129 \\
\hline Male & $65(54 \%)$ & $26(54 \%)$ & 1.000 \\
\hline \multicolumn{4}{|l|}{ Race } \\
\hline White & $61(58 \%)$ & $25(56 \%)$ & 0.740 \\
\hline African American & $34(32 \%)$ & $17(38 \%)$ & \\
\hline Other & $10(10 \%)$ & $3(7 \%)$ & \\
\hline BMI, mean (SD) & $27.5(5.9)$ & $29.4(10.1)$ & 0.133 \\
\hline GCS on adm., mean (SD) & $9.7(3.7)$ & $8.2(3.6)$ & 0.023 \\
\hline Adm. mRS, mean (SD) & $4.92(0.50)$ & $5.0(0)$ & 0.246 \\
\hline SOFA score, mean (SD) & $6.2(2.7)$ & $7.1(2.9)$ & 0.055 \\
\hline NIHSS, mean (SD) & $18.1(6.8)$ & $18.7(8.7)$ & 0.853 \\
\hline \multicolumn{4}{|l|}{ Location } \\
\hline Bilateral supratentorial & $5(4.2 \%)$ & $3(6.3 \%)$ & 0.638 \\
\hline Infratentorial & $23(19.2 \%)$ & $9(18.8 \%)$ & \\
\hline Left supratentorial & $38(31.7 \%)$ & 19 (39.6\%) & \\
\hline Right supratentorial & $54(45.0 \%)$ & 17 (35.4\%) & \\
\hline ICH score, mean (SD) & $1.77(1.00)$ & $1.91(0.82)$ & 0.458 \\
\hline IVH & $41(44.6 \%)$ & $21(56.8 \%)$ & 0.210 \\
\hline Hydrocephalus & $58(63.7 \%)$ & $30(81.1 \%)$ & 0.055 \\
\hline Time to surgery, mean (SD) & $1.23(2.19)$ & $2.85(5.77)$ & 0.009 \\
\hline VAP & $17(14.2 \%)$ & $18(37.5 \%)$ & 0.001 \\
\hline Number of VAP, mean (SD) & $0.38(1.00)$ & $1.02(1.56)$ & 0.002 \\
\hline
\end{tabular}

after tracheostomy will reduce total exposure to risk of VAP. Even though the VAP rates were not significantly different, as was true in our study, we suspect this was due to inadequate study power. Despite lack of direct evidence, we still believe early tracheostomy likely reduces total ventilator time eliminating the primary risk

Table 3 Propensity-weighted outcomes for timing of tracheostomy

\begin{tabular}{llll}
\hline & Early & Late & $p$ value \\
\hline Mortality & $33.3 \%$ & $6.1 \%$ & 0.006 \\
VAP & $40.0 \%$ & $36.4 \%$ & 0.614 \\
Duration of ventilation, mean days (SD) & $7.3(7.2)$ & $15.2(6.6)$ & $<0.001$ \\
ICU stay, mean days (SD) & $20.1(10.6)$ & $31.5(28.1)$ & 0.073 \\
Hospital stay, mean days (SD) & $28.5(12.5)$ & $44.4(33.7)$ & 0.014 \\
$\begin{array}{l}\text { Discharge location } \\
\quad \text { Home/rehabilitation }\end{array}$ & & & \\
$\quad$ Skilled nursing facility/LTAC & $60.0 \%$ & $29.0 \%$ & 0.192 \\
\hline
\end{tabular}

Table 4 Propensity-weighted outcomes for timing of tracheostomy (excluding those who died on comfort care)

\begin{tabular}{llll}
\hline & Early & Late & $p$ value \\
\hline Mortality & $9.1 \%$ & $3.1 \%$ & 0.780 \\
VAP & $36.4 \%$ & $37.5 \%$ & 0.652 \\
Duration of ventilation, mean days (SD) & $5.5(3.4)$ & $15.2(6.7)$ & $<0.001$ \\
ICU stay, mean days (SD) & $20.2(10.2)$ & $32.0(28.4)$ & 0.153 \\
Hospital stay, mean days (SD) & $31.3(11.7)$ & $45.3(33.8)$ & 0.075 \\
$\begin{array}{l}\text { Discharge location } \\
\quad \text { Home/rehabilitation }\end{array}$ & & & \\
$\quad$ Skilled nursing facility/LTAC & $40.0 \%$ & $29.0 \%$ & 0.192 \\
\hline
\end{tabular}

factor for VAP, the ventilator itself. Given the reduction in ICU length of stay, there are likely economic benefits from early tracheostomy as well. This was not explicitly studied here. Ongoing prospective controlled trials are needed to ultimately provide sound evidence for true early tracheostomy in these patients.

The trend in mortality was unexpected, so we reviewed all deaths after our final analysis to try and understand this

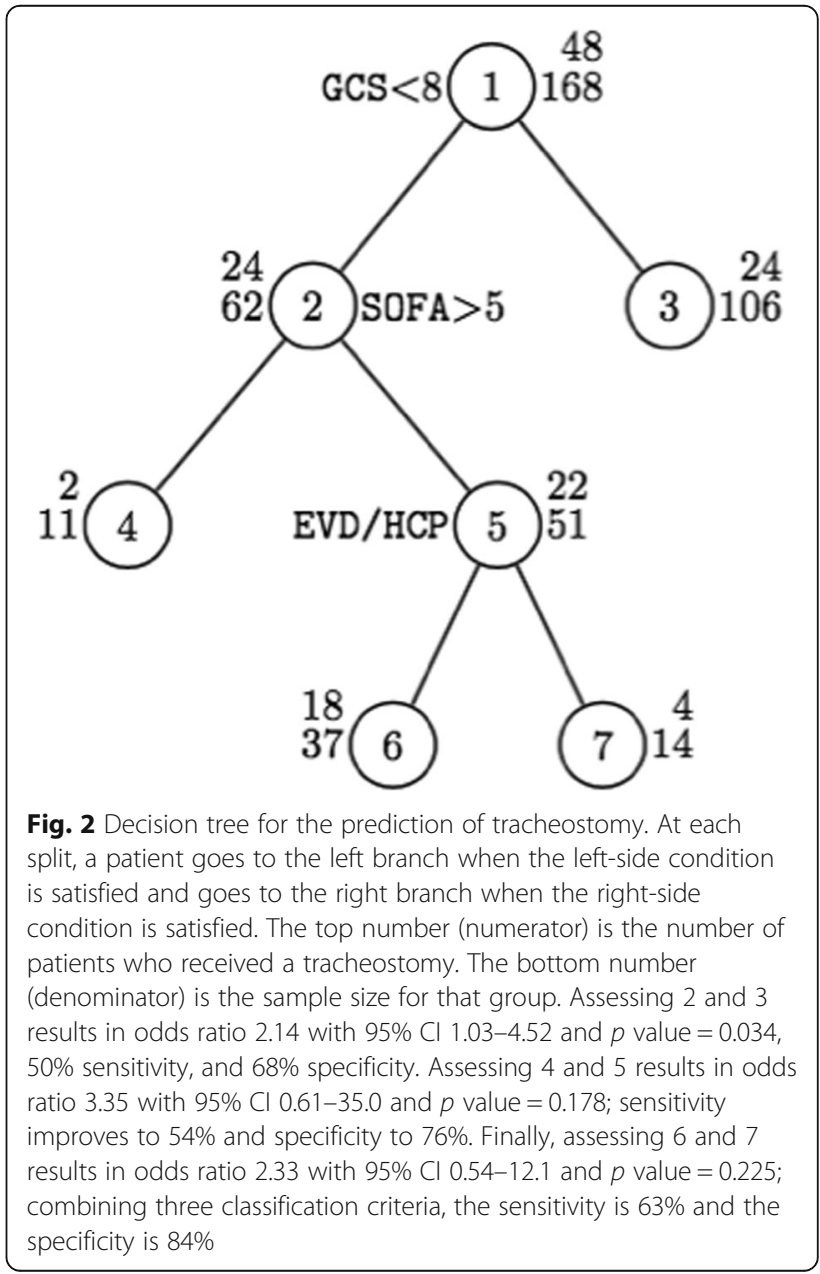



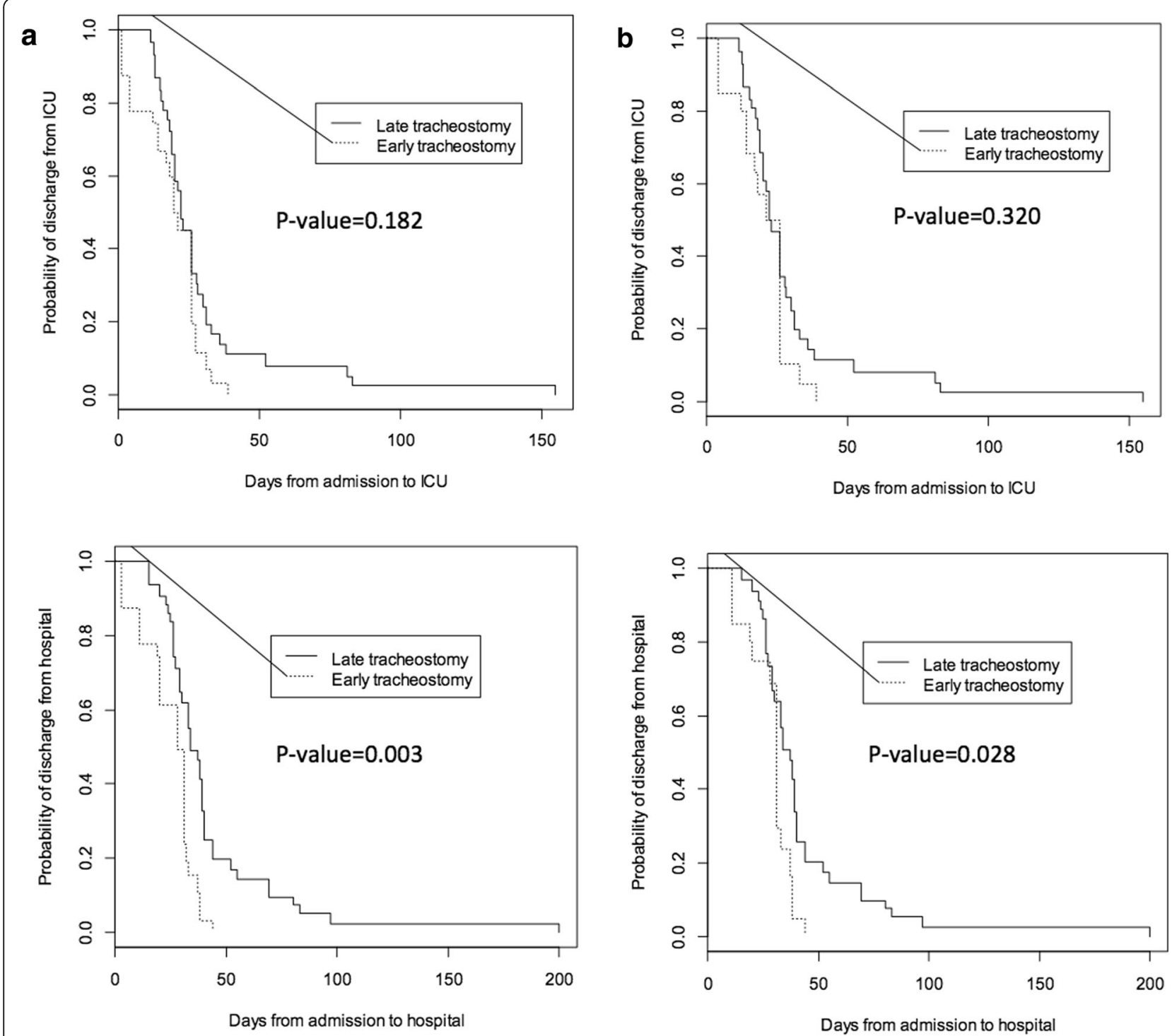

Fig. 3 a Propensity-weighted probability functions for time-to-event for discharge from ICU (top) and discharge from the hospital (bottom) based on timing of tracheostomy. $\mathbf{b}$ Propensity-weighted probability functions for time-to-event for discharge from ICU (top) and discharge from the hospital (bottom) based on timing of tracheostomy (excluding those who died on comfort care)

early mortality phenomenon. We found that a large number of patients died after the family decided to withdraw treatment and transition to comfort care. A total of 42 patients died after decompression, and 37 (88.1\%) of them died after transitioning to comfort measures. Among the five others, only two had tracheostomies making the sample too small to draw conclusions on timing of tracheostomy and mortality (Tables 3 and 4 and Fig. 4). However, even after excluding patients who died on comfort care, duration of mechanical ventilation and ICU and hospital length of stay were still significantly shorter in patients with early tracheostomies (Table 4 and Fig. 3b). In conclusion, our propensity-adjusted dataset shows that those who received an early tracheostomy actually trended toward a higher mortality rate (Table 3; Fig. 4a), but this was completely explained by early transition to comfort measures.

The basis of transition to comfort measures is usually a failure to see measurable improvement combined with a poor expected prognosis. This can materialize in various forms in patients with severe brain injuries. It may result in a "prognostic pessimism" [21] or "self-fulfilling prophecy" [22] in patients who are young and have a reasonable chance of survival. In older patients, where withdrawal of support is unlikely to change the outcome, it may be a reasonable decision based on prolonged suffering without clear long-term benefit. The decision to undergo emergent neurosurgery can be even more challenging, as there is often inadequate time and data to make a decision of such 

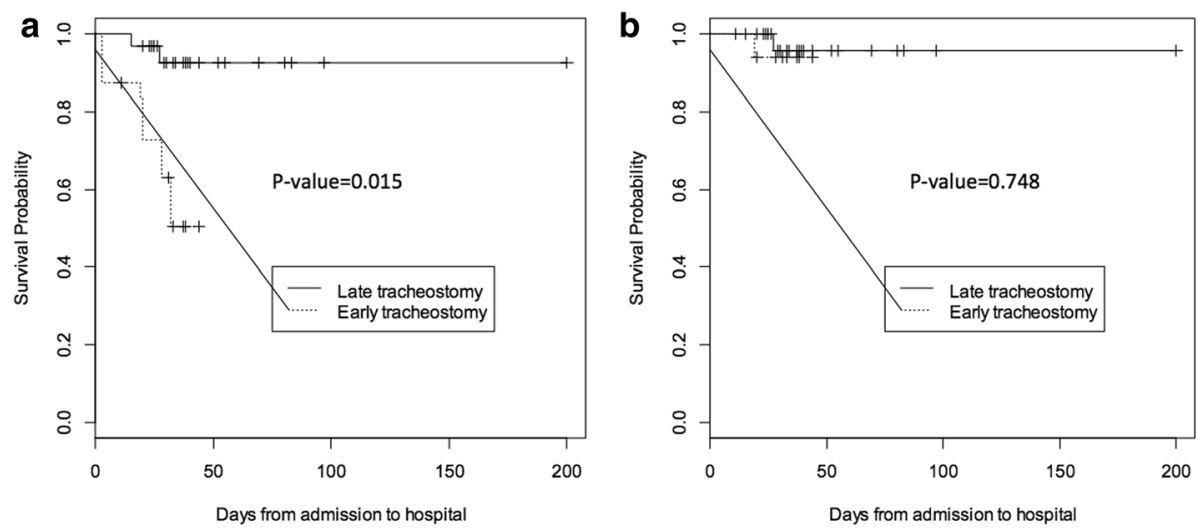

Fig. 4 a Propensity-weighted Kaplan-Meier survival curve. b Propensity-weighted Kaplan-Meier survival curve (excluding those who died on comfort care)

importance. Furthermore, prognostic models ideally would have perfect discrimination, with a $0 \%$ false positive rate for poor outcome [21]. However, this is currently only available for patients with anoxic brain injury after cardiopulmonary resuscitation, and oftentimes, families just need time under aggressive treatment to cope with the finality of the patient's condition [21].

Our mean patient age was 55 years old, which puts the majority of our patients within the data-supported range for mortality benefit from decompression for ischemic stroke [23-25]. For intracranial hemorrhage, the benefit of surgical decompression is less clear and is often a last resort in the face of cerebral herniation and brainstem compression. When asked about the maximum age compatible with meaningful survival in patients with intracerebral hemorrhage, responders quoted about 70 years [4]. These same authors found that medical support was ultimately withdrawn in about $76.7 \%$ of patients who died, which is close to our finding of $88.1 \%$. The decision of medical futility will ultimately fall on the surgeon and intensivist providing the treatment. Predicting tracheostomy dependence may help families with the surgical decision as well, although, even with our decision tree analysis, models remain imperfect. Sometimes, even after maximal intervention and attempts sustain the life of stroke patients, the lack of measureable improvement and small setbacks breach the threshold families have for continuing with the treatment they once desired for their loved one.

\section{Conclusions}

The natural history of acute ischemic and hemorrhagic stroke requiring surgical decompression carries a grim prognosis. Early tracheostomy seems to have a few measurable benefits, namely shorter duration of mechanical ventilation and shorter length of stay. These may, however, be significant enough to families, and early tracheostomy may be reasonable to consider. We developed a decision tree analysis that can be used by neurosurgeons and neurointensivists to aid families in their decision-making prior to surgery. Upon ICU admission, surrogate decision-makers often have little time to process these tragic circumstances, and committing someone to a major operation, even if life saving, is often a difficult choice to make. An artificial airway is a concrete outcome laypersons can understand. We believe that these types of tools are useful to inform surrogates, guide appropriate care, and limit unnecessarily aggressive interventions leading to early post-operative withdrawal of treatment and early death.

\section{Additional file}

Additional file 1: Table S1. Bivariate analysis for ventilator associated pneumonia. Table S2. Outcome analysis with and without tracheostomy using proposed propensity score. (DOCX $15 \mathrm{~kb}$ )

\section{Abbreviations}

GCS: Glasgow Coma Score; ICU: Intensive care unit; SOFA: Sequential Organ Failure Assessment; VAP: Ventilator-associated pneumonia

\section{Acknowledgements}

Not applicable

Funding

The authors provided all the financial support for this study.

Availability of data and materials

The datasets used in this study are available from the corresponding author on reasonable request.

Authors' contributions

MPC and JDJ contributed to the study design, data collection, and data analysis; wrote and reviewed the manuscript; and submitted the manuscript. FCL contributed to data analysis and reviewed the manuscript. ND contributed to the study design and data collection and reviewed the manuscript. KA contributed to data collection and reviewed the manuscript. COS contributed to the study design and reviewed the manuscript. All authors read and approved the final manuscript.

Ethics approval and consent to participate

This study was approved by the Institutional Review Board of University of North Carolina at Chapel Hill with study number 15-2372. 


\section{Consent for publication}

Not applicable.

\section{Competing interests}

The authors declare that they have no competing interests.

\section{Publisher's Note}

Springer Nature remains neutral with regard to jurisdictional claims in published maps and institutional affiliations.

\section{Author details}

'Department of Neurosurgery, University of North Carolina School of Medicine, 170 Manning Drive, Campus Box 7025, Chapel Hill, NC 27599-7025, USA. ${ }^{2}$ Department of Biostatistics, Gillings School of Global Public Health, Chapel Hill, NC, USA. ${ }^{3}$ School of Medicine, University of North Carolina School of Medicine, Chapel Hill, NC, USA. ${ }^{4}$ Department of Neurology, University of North Carolina, 170 Manning Drive, Campus Box 7025, Chapel Hill, NC, USA.

\section{Received: 30 August 2017 Accepted: 7 December 2017}

Published online: 04 January 2018

\section{References}

1. Alsumrain M, Melillo N, Debari VA, Kirmani J, Moussavi M, Doraiswamy V, et al. Predictors and outcomes of pneumonia in patients with spontaneous intracerebral hemorrhage. J Intensive Care Med. 2013;28(2):118-23.

2. Cocoros NM, Klompas M. Ventilator-associated events and their prevention. Infect Dis Clin N Am. 2016;30(4):887-908.

3. Rabinstein AA, Wijdicks EF. Outcome of survivors of acute stroke who require prolonged ventilatory assistance and tracheostomy. Cerebrovasc Dis. 2004; 18:325-31.

4. Kalanuria AA, Zai W, Mirski M. Ventilator-associated pneumonia in the ICU. Crit Care. 2014;18(2):208.

5. van der Lely AJ, Veelo DP, Dongelmans DA, Korevaar JC, Vroom MB, Schultz MJ. Time to wean after tracheotomy differs among subgroups of critically ill patients: retrospective analysis in a mixed medical/surgical intensive care unit. Respir Care. 2006;51(12):1408-15.

6. Torbey MT, Bösel J, Rhoney DH, Rincon F, Staykov D, Amar AP, et al. Evidence-based guidelines for the management of large hemispheric infarction. Neurocrit Care. 2015;22(1):146-64.

7. Young D, Harrison DA, Cuthbertson BH, Rowan K. Effect of early vs late tracheostomy placement on survival in patients receiving mechanical ventilation. JAMA. 2013;309(20):2121-9.

8. Andriolo BN, Andriolo RB, Saconato H, Atallah ÁN, Valente O. Early versus late tracheostomy for critically ill patients (review). Cochrane Database Syst Rev. 2015;(1):1-67. Art. No.: CD007271.

9. Bösel J, Schiller P, Hook Y, Andes M, Neumann JO, Poli S, et al. Strokerelated Early Tracheostomy versus Prolonged Orotracheal Intubation in Neurocritical Care Trial (SETPOINT): a randomized pilot trial. Stroke. 2012;44(1):21-8

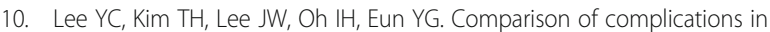
stroke subjects undergoing early versus standard tracheostomy. Respir Care. 2015;60(5):651-7.

11. Villwock JA, Villwock MR, Deshaies EM. Tracheostomy timing affects stroke recovery. J Stroke Cerebrovasc Dis. 2014;23(5):1069-72.

12. Alshekhlee A, Horn C, Jung R, Alawi AA, Cruz-Flores S. In-hospital mortality in acute ischemic stroke treated with hemicraniectomy in US hospitals. J Stroke Cerebrovasc Dis. 2011;20(3):196-201.

13. Qureshi Al, Suarez Jl, Parekh PD, Bhardwaj A. Prediction and timing of tracheostomy in patients with infratentorial lesions requiring mechanical ventilatory support. Crit Care Med. 2000;28(5):1383-7.

14. Szeder V, Ortega-Gutierrez S, Ziai W, Torbey MT. The TRACH score: clinical and radiological predictors of tracheostomy in supratentorial spontaneous intracerebral hemorrhage. Neurocrit Care. 2010;13(1):40-6.

15. Schonenberger S, Al-Suwaidan F, Kieser M, Uhlmann L, Bösel J. The SETscore to predict tracheostomy need in cerebrovascular neurocritical care patients. Neurocrit Care. 2016;25(1):94-104.

16. Huttner HB, Kohrmann M, Berger C, Georgiadis D, Schwab S. Predictive factors for tracheostomy in neurocritical care patients with spontaneous supratentorial hemorrhage. Cerebrovasc Dis. 2006;21:159-65.
17. Meng L, Wang C, Li J, Zhang J. Early vs late tracheostomy in critically ill patients: a systematic review and meta-analysis. Clin Respir J. 2015; 10(6):684-92

18. Huang Y-H, Lee T-C, Liao C-C, Deng Y-H, Kwan A-L. Tracheostomy in craniectomised survivors after traumatic brain injury: a cross-sectional analytical study. Injury. 2013:44(9):1226-31. https:/doi.org/10.1016/j.injury.2012.12.029.

19. McCredie VA, Alali AS, Scales DC, Adhikari NK, Rubenfeld GD, Cuthbertson $\mathrm{BH}$, et al. Effect of early versus late tracheostomy or prolonged intubation in critically ill patients with acute brain injury: a systematic review and metaanalysis. Neurocrit Care. 2017;26(1):14-25.

20. Pinheiro Bdo V, Tostes Rde O, Brum Cl, Carvalho EV, Pinto SP, Oliveira JC. Early versus late tracheostomy in patients with acute severe brain injury. J Bras Pneumol. 2010;36(1):84-91.

21. Geurts M, Macleod MR, van Thiel GJMW, van Gijn J, Kappelle $\sqcup$, van der Worp HB. End-of-life decisions in patients with severe acute brain injury. Lancet Neurol. 2014;13(5):515-24.

22. Becker KJ, Baxter AB, Cohen WA, Bybee HM, Tirschwell DL, Newell DW, et al. Withdrawal of support in intracerebral hemorrhage may lead to self-fulfilling prophecies. Neurology. 2001;56:766-72.

23. Hofmeijer J, Kappelle LJ, Algra A, Amelink GJ, van Gijn J, van der Worp HB. Surgical decompression for space-occupying cerebral infarction (the Hemicraniectomy After Middle Cerebral Artery infarction with Lifethreatening Edema Trial [HAMLET]): a multicentre, open, randomised trial. Lancet Neurol. 2009:8(4):326-33.

24. Jüttler E, Schwab S, Schmiedek P, Unterberg A, Hennerici M, Woitzik J, et al. Decompressive Surgery for the Treatment of Malignant Infarction of the Middle Cerebral Artery (DESTINY): a randomized, controlled trial. Stroke. 2007;38(9):2518-25.

25. Vahedi K, Vicaut E, Mateo J, Kurtz A, Orabi M, Guichard JP, et al. Sequentialdesign, multicenter, randomized, controlled trial of early Decompressive Craniectomy in Malignant Middle Cerebral Artery Infarction (DECIMAL trial). Stroke. 2007;38(9):2506-17.

\section{Submit your next manuscript to BioMed Central and we will help you at every step:}

- We accept pre-submission inquiries

- Our selector tool helps you to find the most relevant journal

- We provide round the clock customer support

- Convenient online submission

- Thorough peer review

- Inclusion in PubMed and all major indexing services

- Maximum visibility for your research

Submit your manuscript at www.biomedcentral.com/submit
Ciomed Central 